\title{
The psychomotor disorders: disorders of the supervisory mental processes
}

\author{
P.F. Liddle \\ Royal Postgraduate Medical School, Hammersmith Hospital, Ducane Rd, \\ London W12 OHS, UK
}

\begin{abstract}
Clinical evidence suggests that three major patterns of disturbance of the supervisory mental processes that regulate selfgenerated mental activity can occur, either alone or together, in a variety of neurological and psychiatric conditions. Psychomotor poverty involves a diminished ability to initiate activity. Psychomotor disorganization reflects impaired ability to select between activities. Reality distortion, which is manifest as delusions and hallucinations, appears to reflect an abnormality of internal monitoring of mental activity. Each of these three syndromes is associated with a specific pattern of disordered function in multimodal association cortex and related subcortical nuclei. The evidence suggests that the neurotransmitter dopamine plays a major role in modulating the supervisory mental processes, though serotonin and noradrenaline are also implicated. While a particular neurotransmitter might have conflicting influences on different syndromes, the differential involvement of different anatomic sites and different neuroreceptor types offers the possibility of successful treatment even when different syndromes co-exist.
\end{abstract}

Keywords: Association cortex - Basal ganglia - Depression - Dopamine - Frontal lobes - Psychomotor disorder Schizophrenia

\section{INTRODUCTION}

The supervisory mental processes are concerned with the initiation, organization and monitoring of self-generated mental activity. In contrast to routine mental functions such as perception, the laying down of memory traces, execution of a well-learned motor act, and logical reasoning, in which the objective of the process is largely predetermined by circumstances, the supervisory mental processes are most relevant when there is ambiguity in what is required. Disorders of these processes are most apparent under circumstances that call for initiative.

Disorders of the supervisory mental processes occur in a variety of neurological and psychiatric conditions. In some instances, the disorders result from destruction of brain tissue, as in the famous case of Phineas Gage, the American railway worker who suffered damage to his frontal lobes when the premature detonation of an explosive charge drove a steel tamping rod through his skull. He had been a reliable and responsible man, but was transformed into a feckless individual lacking in social grace (Harlow, 1848). Similar patterns of behaviour occur in conditions in which there is less extensive damage to neurons. Although the disorders often arise from neuronal destruction, degeneration or dysplasia, the evidence suggests that the characteristic clinical features reflect imbalance of the monoamine neurotransmitters which modulate mental activity.
In many instances, these disorders are persistent, cause serious disruption of the life of the sufferer, and impose a heavy burden on those caring for them. In the past, these disorders have often evoked a pessimistic response from health care professionals, because of limited understanding of the nature of the problems and poor response to treatment. Recent advances in neuroscience, including advances in brain imaging, have provided a foundation for better understanding and treatment. This paper reviews the clinical features of disorders of the supervisory mental processes in various neurological and psychiatric conditions, presents a speculative synthesis of information concerning the neural basis of these disorders, and examines potential strategies for treatment.

\section{PSYCHOMOTOR DISORDERS IN SCHIZOPHRENIA}

More than 100 years ago, Hecker (1871) described hebephrenia, a disorder characterized by silly behaviour, fragmentary delusions and self-neglect. His contemporary Kahlbaum (1874) identified catatonia, a disorder of the control of voluntary movement. Early in this century, Kraepelin (1919) combined hebephrenia, catatonia and deteriorating paranoid disorders into a single entity which 
we now call schizophrenia. Kraepelin (1920) considered that the essential feature of schizophrenia is "that destruction of conscious volition ... which is manifest as a loss of energy and drive, in disjointed volitional behaviour".

More recently, Liddle and colleagues have carried out a series of studies designed to delineate the nature of the neuropathological processes that generate the symptoms of schizophrenia. On the assumption that several distinguishable though related pathological processes occur in schizophrenia, Liddle $(1984,1987$ a) examined the relationships between persistent schizophrenic symptoms, and demonstrated' that these symptoms segregate into three syndromes: psychomotor poverty (poverty of speech, flat affect, decreased spontaneous movement), disorganization (disorders of the form of thought, inappropriate affect) and reality distortion (delusions, hallucinations). The component symptoms of these syndromes resemble the clinical features of the three classical types of psychotic illness which Kraepelin had amalgamated to form schizophrenia. Although distinguishable, the three syndromes often co-exist, implying that they share some common feature, supporting Kraepelin's conclusion that they belong to a single category of illness. Other studies (Bilder et al., 1985; Arndt et al., 1991; Peralta et al., 1992) have reported a similar segregation of schizophrenic symptoms into three syndromes.

Each syndrome is associated with a specific pattern of neuropsychological impairment (Liddle, 1987b), implying that each arises from a different pattern of brain malfunction. In a study of performance in tests of frontal lobe function Liddle and Morris (1991) found that psychomotor poverty is associated with impaired ability to initiate activity, whilst disorganization is associated with impaired ability to suppress inappropriate responses. Meanwhile, in a study of patients with delusions and hallucinations, Frith and Done (1989) obtained evidence suggesting that reality distortion symptoms arise from impaired monitoring of self-generated mental activities.

In a study using positron emission tomography (PET), Liddle et al. (1992a) demonstrated that each of the three syndromes is associated with a specific pattern of regional cerebral blood flow (rCBF) in areas of association cortex and related subcortical nuclei. Psychomotor poverty was associated with decreased rCBF in the left dorsolateral and medial prefrontal cortex and parietal cortex, and with increased rCBF in the corpus striatum. Disorganization is associated with decreased $\mathrm{rCBF}$ in the right ventral prefrontal cortex and contiguous insula, and with increased rCBF in the right anterior cingulate cortex and thalamus. Reality distortion is associated with increased $\mathrm{rCBF}$ in the left medial temporal lobe and frontal cortex.

In addition to the three psychomotor syndromes typical of chronic schizophrenia, there is a fourth syndrome, psychomotor excitation, characterized by motor overactivity, pressure of speech and heightened labile effect, that occurs during acute schizophrenic episodes, but is transient in nature. Its neural basis has been less thoroughly investigated.

\section{PSYCHOMOTOR DISORDERS FOLLOWING FRONTAL LOBE INJURY}

Psychomotor disorders have long been recognized in patients with frontal lobes damaged by trauma, tumour or vascular disease. Kleist (1934) attempted to delineate the relationship between the location of the damage and associated changes in personality. He found that patients with orbital frontal lesions were likely to exhibit puerile facetious behaviour, and unstable mood. Patients with more dorsal lesions tended to have impoverished, stereotyped thinking and to lack initiative.

Blumer and Benson (1975) distinguished two frontal lobe syndromes: pseudodepression characterized by apathy, indifference, slowness and decreased tendency to initiate conversation; and the pseudopsychopathic syndrome characterized by puerility, euphoria and garrulous speech. Pseudodepression closely resembles the psychomotor poverty syndrome seen in schizophrenia, while the pseudopsychopathic syndrome resembles the disorganization syndrome. There is controversy concerning the location within the frontal lobe of lesions likely to produce these two frontal syndromes. In accord with Kleist, Blumer and Benson propose that pseudodepression arises from lesions of the dorsal frontal lobe, while orbital lesions result in the pseudopsychopathic syndrome. In contrast, Kolb and Whishaw (1980) suggest that pseudodepression arises from left frontal lesions and the pseudopsychopathic syndrome arises from right frontal lesions.

In a neurolinguistic analysis of the speech of patients with frontal lesions, Kaczmarek (1984) found that patients with left dorsolateral prefrontal lesions produce an excess of simple sentences or sentence fragments, and show perseveration of propositions, a pattern similar to speech in the psychomotor poverty syndrome. Patients with left orbital frontal lesions show poor control of speech with changes of course in response to external or internal impulses, resembling the tangentiality and derailment typical of the disorganization syndrome. Kaczmarek also found evidence that right frontal lobe lesions produce impairment of the global organization of the information to be uttered.

Thus, frontal lobe lesions produce at least two distinguishable patterns of impairment. One, characterized by decreased mental activity, appears to be associated with left dorsal lesions. The other, characterized by disorganization of mental activity, is associated with orbital and/or right-sided lesions. 


\section{PSYCHOMOTOR DISORDERS ASSOCIATED WITH TEMPORAL LOBE EPILEPSY}

Temporal lobe epilepsy can be associated with a schizophreniform psychosis characterized by delusions and hallucinations (reality distortion) but little evidence of either disorganization or psychomotor poverty. Trimble (1992) has reviewed the evidence that epileptic patients with psychosis, especially those with Schneiderian first rank symptoms, have structural and functional abnormalities of the left temporal lobe. In particular, Gallhofer et al. (1985) found an association between psychosis in epilepsy and left temporal metabolic deficits. These findings are consistent with the evidence that reality distortion in schizophrenia is associated with altered rCBF in the left temporal lobe (Liddle et al., 1992a). It should be noted that Liddle et al. found an increase in left temporal $\mathrm{rCBF}$ in patients with persistent stable symptoms, whereas Gallhofer et al. found decreased left temporal metabolism in patients who were not necessarily suffering symptoms at the time of scanning. This would be consistent with a switch from cerebral underactivity to overactivity at time of symptom expression.

\section{PSYCHOMOTOR DISORDERS ASSOCIATED WITH BASAL GANGLION DEGENERATION}

The frequent occurrence of psychomotor disorders in basal ganglia disorders has led to the concept of subcortical dementia (Huber and Paulson, 1985), characterized by slowing of mental operations, apathy, depression and memory impairment. There has been debate as to whether or not this clinical pattern is a direct expression of basal ganglion malfunction, or a consequence of secondary cortical malfunction. If supervisory mental functions are mediated by neuronal networks distributed in association cortex and related subcortical nuclei, this debate is perhaps irrelevant, since basal ganglion disorder might be expected to produce malfunction of the relevant network. Patients with Parkinson's disease who have difficulty initiating actions fail to show the normal activation of the medial and dorsolateral frontal cortex and the putamen during a task that demands selection and initiation of action (Playford et al., 1992). This demonstrates that there is cortical underfunction in patients suffering from difficulty initiating activity associated with basal ganglion disorder.

Degenerative basal ganglion disorders typically produce a picture of psychomotor poverty. In a study of the prevalence of psychological symptoms in Huntington's chorea, Caine and Shoulson (1983) found that apathy and inertia were the most common, but they also found features characteristic of the disorganization syndrome, such as impaired organization of verbal material and lability of affect.

\section{PSYCHOMOTOR DISORDERS IN DEMENTIA}

A substantial minority of patients with presenile dementia present a clinical picture dominated by personality change with unconcern, disinhibition, and economic, concrete speech (Neary et al., 1988). These patients have reduced frontal rCBF (Neary et al., 1988). At post-mortem examination, some of these patients show the histological changes of Pick's disease, but some do not.

\section{PSYCHOMOTOR DISORDERS IN DEPRESSION AND IN MANIA}

Psychomotor retardation, which entails slowing and diminution of thought and action, is a well-recognized feature of depression. PET studies of depression (Baxter et al., 1988) have shown hypometabolism in the frontal lobes, which appears to resolve on recovery. Bench et al. (in press) have shown that severity of retardation in depression is correlated with decreased rCBF in the left dorsolateral prefrontal cortex, and in the left parietal lobe in a pattern virtually identical with that associated with psychomotor poverty in schizophrenia, though unlike the situation in schizophrenia, there is no evidence of basal ganglia hyperperfusion. These findings suggest that there is an overlap in the pathophysiological process underlying impaired initiation of mental activity in depression and in schizophrenia.

On the other hand, Berman et al. (1993) found that depressed patients, unlike patients with schizophrenia, do not suffer a decreased ability to activate prefrontal cortex during the performance of the Wisconsin card sorting test. They argued that the mechanisms underlying prefrontal dysfunction in depression and in schizophrenia are likely to be different. This conclusion must be regarded with caution because in their sample of 10 depressed patients, there was no evidence of decreased frontal perfusion at rest, whereas other studies (e.g. Baxter et al., 1989) have found frontal underactivity at rest in depression, at least in those cases exhibiting psychomotor retardation (Bench et al., in press). Clinical observation indicates that psychomotor poverty in depression is usually less persistent than psychomotor poverty in schizophrenia suggesting that the primary cause is more persistent in schizophrenia, but this does not preclude possibility that there is substantial overlap in the mechanism of symptom production in both disorders.

In mania, there is not only psychomotor excitation, but also disorganization of activity, and in some cases, delusions and hallucinations. The distractibility and formal thought disorder of mania are very similar to the disorganization symptoms of schizophrenia (Andreasen, 1979). The major feature that distinguishes the thought disorder of mania from that of schizophrenia is that in mania the tendency to derailment is accompanied by rap- 
idity of thought, whereas in schizophrenia thinking tends to exhibit poverty of content and lack of linguistic complexity (Morice and Ingram, 1982). Thus, the observed differences between manic and schizophrenic thought disorder might be accounted for by the greater tendency for disorganization in schizophrenia to co-exist with psychomotor poverty whereas in mania, disorganization coexists with psychomotor excitation.

\section{THE NEUROANATOMICAL BASIS OF PSYCHOMOTOR DISORDERS}

The clinical evidence suggests that psychomotor disorders, especially psychomotor poverty and disorganization, are associated with aberrant activity of association cortex, especially in the frontal lobes, and related subcortical nuclei. Luria's (1966) studies of patients with frontal lobe lesions led him to propose that the frontal lobes are responsible for programming, regulation and verification of activity. More recently, Norman and Shallice (1980) have proposed the existence of a frontal supervisory attentional system which modulates a lower level contention scheduling system responsible for selection of routine actions. The supervisory attentional system is involved in generating willed actions and in making decisions in situations where routine procedures for selecting action would be unsatisfactory. Shallice (1989) described two types of abnormality that would be expected to result from failure of the supervisory system: behavioural rigidity with a tendency to perseverate, and distractibility with a tendency to be side-tracked into irrelevant associations.

Studies of primates confirm that the frontal lobes play an important role in supervisory mental functions. On the basis of an extensive review, Fuster (1980) proposed that the dorsal and orbital aspects of the prefrontal cortex have distinguishable roles. He concluded that the dorsal prefrontal cortex is concerned with time sequencing, while the ventral prefrontal cortex is concerned with the inhibition of inappropriate responses. Goldman-Rakic (1988) has identified a distributed network embracing prefrontal, cingulate, parietal and temporal cortex which is responsible for regulation of behaviour in primates.

PET has been used to study the pattern of rCBF in normal human subjects during the performance of various tasks that depend heavily on supervisory mental functions. Frith et al. (1991) demonstrated that the internal generation of words, and also the internal generation of a sequence of motor acts, was accompanied by activation of the dorsolateral and medial prefrontal cortex. The area of left dorsolateral prefrontal cortex activated in normal individuals during the internal generation of words coincided with the area in which $\mathrm{rCBF}$ is negatively correlated with severity of psychomotor poverty in schizophrenia (Liddle et al., 1992a,b).
Pardo et al. (1990) found that the right anterior cingulate cortex is the cerebral area most strongly activated in normal individuals performing the Stroop task, which demands the suppression of a tendency to respond to irrelevant aspects of a stimulus. The site of maximal activation lies within the area of anterior cingulate cortex that is overactive in schizophrenic patients with the disorganization syndrome (Liddle et al., 1992a,b), suggesting that patients with disorganization are continually engaged in a struggle to suppress inappropriate responses.

Frith et al. (1992) demonstrated that in normal individuals engaged in learning a novel eye-movement task

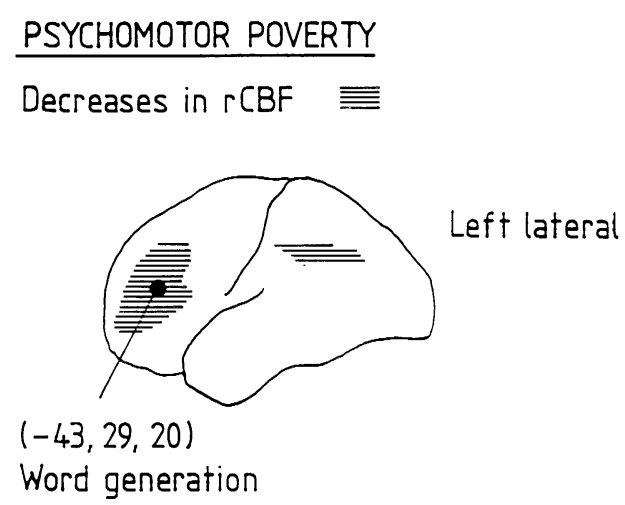

FIG. 1. Locus of maximal activation of the prefrontal cortex during the internal generation of words in normal subjects superimposed on the areas of decreased cortical blood flow associated with psychomotor poverty in schizophrenia. Coordinates specify distance in millimetres from an origin at the midpoint of the anterior commissure with reference to a coordinate frame whose $x$ axis is directed from left to right, $y$ axis is directed from posterior to anterior and $z$ axis is perpendicular to the horizontal plane containing the anterior and posterior commissures. (Reprinted from Liddle et al. (1992b) with permission.)

\section{DISORGANIZATION}

\section{Increases in rCBF |||||}

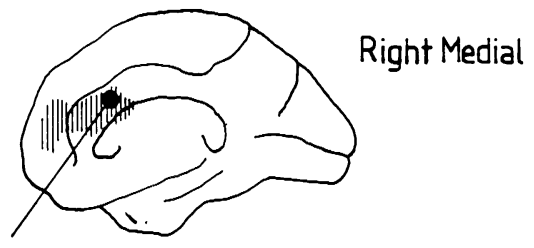

$(10,18,30)$

Stroop test

FIG. 2. Locus of maximal activation of the anterior cingulate cortex during performance of the Stroop test superimposed on the area of increased cortical blood flow associated with disorganization in schizophrenia. (Reprinted from Liddle et al. (1992b) with permission.) 


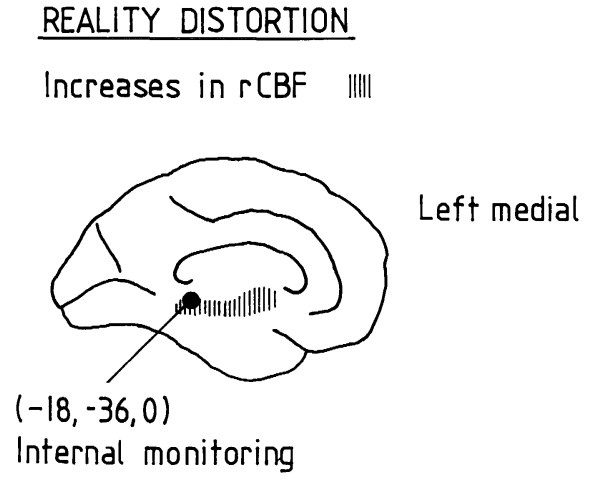

FIG. 3. Locus of maximal activation of the parahippocampal gyrus during the internal monitoring of eye movements superimposed on the area of increased medial temporal blood flow associated with reality distortion in schizophrenia. (Reprinted from Liddle et al. (1992b) with permission.)

which would be expected to make heavy demands upon the internal monitoring of self-generated activity, there is increased $\mathrm{rCBF}$ in various areas of association cortex. The locus of maximum activation (apart from association areas specifically concerned with detection of movement of visual stimuli and with eye movement) is in the left parahippocampal gyrus at a site coinciding with the site of increased rCBF in schizophrenic patients with delusions and hallucinations (Liddle et al., 1992a,b) suggesting that patients with delusions and hallucinations engage in a pathological degree of internal monitoring of their own mental activity.

\section{THE PHARMACOLOGY OF PSYCHOMOTOR DISORDERS}

\section{Neuromodulation}

On conceptual grounds, it might be expected that neuromodulatory neurotransmitters would play a major role in the processes responsible for the initiation and selection of mental activity. A neuromodulator regulates the electrical properties of neurons to allow the choice of different responses under different circumstances. Much evidence suggests that dopamine can act as a neuromodulator. For example, Morgenson and Yim (1981) demonstrated that in rats release of dopamine in the nucleus accumbens by stimulation of the ventral tegmental area produces no direct excitatory or inhibitory responses in neurons in the nucleus accumbens under resting conditions, but does attenuate the excitation in the accumbens generated by stimulation of the amygdala. Thus, it appears that the dopamine released in the nucleus accumbens in rats (homologous with the ventral striatum in humans) modulates the action of the glutaminergic neurons projecting from amygdala to nucleus accumbens.
Using PET, Friston et al. (1992) have obtained evidence suggesting that apomorphine, a dopamine agonist, and also buspirone, a 5-HT $\mathrm{HA}_{1 \mathrm{~A}}$ serotonin agonist, exert neuromodulatory actions in humans. They showed that apomorphine attenuates the prefrontal activation during a memory task, while buspirone attenuates the parahippocampal and retrosplenial activation during the same memory task.

\section{Effects of dopamine agonists on motor activity}

Robbins and Sahakian (1983) have reviewed the behavioural effects of drugs, such as amphetamine and L-dopa, which enhance dopaminergic neurotransmission, in animals and in humans. In general, gross locomotor activity shows an inverted U-shaped relationship to dose. As dose increases, locomotor activity initially increases, but then decreases as locomotion gives way to stereotyped behaviour. It is clear that the entire spectrum of abnormal behaviours in response to psychomotor stimulants does not reflect a continuum of activity in a single neuronal system. There are three relevant dopaminergic systems: nigrostriatal, mesolimbic and mesocortical. In rats, dopamine depletion in the nucleus accumbens (mesolimbic system) attenuates the locomotor activity produced by low doses of amphetamine (Kelly et al., 1975) while depletion in the corpus striatum attenuates stereotypic sniffing and head movements induced by high dose amphetamine (Creese and Iverson, 1974).

\section{Cortical modulation of subcortical dopaminergic activity}

Not only does the evidence suggest that dopamine can act as a neuromodulator, but there is evidence indicating that subcortical dopaminergic activity is itself modulated by cortico-subcortical glutaminergic projections. Although the original findings reported by Pycock et al. (1980) that 6-hydroxydopamine-induced lesions of the prefrontal cortex increase dopamine turnover and dopamine receptor density in the rat striatum have not been confirmed, subsequent studies have shown that fronto-subcortical projections do influence dopamine receptors in the basal ganglia. For example, Reibaud et al. (1984) found that dopaminergic denervation of the nucleus accumbens (produced by lesioning the ventral tegmental area) does not produce the expected denervation hypersensitivity of accumbens D1 dopamine receptors while the prefrontal cortex remains intact. However, after prefrontal lesions that destroy the fronto-subcortical glutaminergic projections, dopaminergic denervation of the nucleus accumbens does produce D1 hypersensitivity.

\section{Dopaminergic involvement in psychomotor disorders in humans}

Several studies (Van Praag et al., 1975; Banki, 1977) have shown that dopamine turnover, as measured by the con- 
centration of homovanillic acid (HVA) in the CSF, is decreased in depressed patients with psychomotor retardation, but not in those without retardation. Wolfe et al. (1990) demonstrated that low HVA in CSF was associated with poor performance in frontal lobe tests in depression, Parkinson's disease and in dementia.

The dopamine precursor L-dopa is an effective treatment in some cases of depression, especially those with motor retardation (Goodwin et al., 1970; Matussek et al., 1970). Indirect dopamine agonists such as amphetamine produce rapid clinical improvement in apathetic, depressed elderly patients (Askinazi et al., 1986; Chiarello and Cole, 1987). In Parkinson's disease, L-dopa relieves not only hypokinesia, but also a "simple" depressive state, resembling psychomotor poverty, characterized by asthenia, inertia and sadness, though it does not relieve major depression associated with depressive cognitions such as guilt (de Aguriaguerra, 1971).

In schizophrenia, low levels of HVA in the CSF are associated with catatonic symptoms and underactivity (Lindstrom, 1985) and with failure to activate the prefrontal cortex during performance in the Wisconsin card sorting test, which demands flexibility in problem solving (Weinberger et al., 1988). Furthermore, Daniel et al. (1990) found that dextroamphetamine alleviated the failure of frontal activation during this task. Geraud et al. (1987) found that the dopamine agonist piribedil reversed the relative frontal hypoperfusion in chronic schizophrenic patients in the resting state.

Goldberg et al. (1991) demonstrated that a single dose of dextroamphetamine administered to schizophrenic patients receiving sustained treatment with haloperidol, produced a modest improvement in affect and in performance of the Wisconsin card sorting test. They argued that it was likely that these effects were mediated by activation of cortical dopamine D1 receptors, since the haloperidol would be expected to have blocked subcortical dopamine D2 receptors. This interpretation is consistent with the observation by Sawaguchi and Goldman-Rakic (1991) that the D1 agonists SCH23390 and SCH39166 produce improved performance in working memory tasks when injected in the prefrontal cortex of monkeys.

Crow (1980) proposed that in schizophrenia poverty of speech and flat affect (cardinal features of the psychomotor poverty syndrome) reflect structural brain damage which is manifest as ventricular enlargement. Even if the fundamental cause of such symptoms is irreversible structural damage, this would not preclude the possibility that the mechanism of symptom expression entails a disturbance of function that can be alleviated by pharmacological means. In fact, Goldberg et al. (1991) found that ventricular enlargement was a predictor of responsiveness to dextroamphetamine, confirming that structural damage can be associated with reversible biochemical imbalance.
Overall, the effects of dopamine agonists on psychomotor disorders are complex. While the bulk of the evidence suggests that dopamine agonists are likely to relieve psychomotor poverty symptoms, they are likely to exacerbate other psychomotor symptoms. In the case of schizophrenia, dopamine agonists cause improvement in chronic patients who are withdrawn and apathetic (Cesarec and Nyman, 1985) but exacerbate symptoms such as delusions and hallucinations in other cases (Janowsky and Davis, 1976). Chronic administration of amphetamine tends to produce a syndrome resembling mania. As documented in a review by Fibiger (1991), the clinical features include psychomotor excitation and thought disorders typical of the disorganization syndrome, as well as delusions and hallucinations.

In general, the evidence suggests that psychomotor poverty is associated with dopaminergic underactivity, while psychomotor excitation, disorganization and reality distortion are associated with dopaminergic overactivity. However, it is important to realize that disorganization and reality distortion can occur alone or can co-exist with each other, and with either psychomotor excitation or psychomotor poverty. The various psychomotor disorders reflect at least three distinct dimensions of psychopathology (Liddle, 1984, 1987a). The extent to which psychomotor poverty and psychomotor excitation are opposite poles of a single dimension has yet to be determined.

\section{The role of other monoamine neurotransmitters}

The well-known hallucinogenic properties of serotonin $5-\mathrm{HT}_{1 \mathrm{C}}$ and $5-\mathrm{HT}_{2}$ receptor agonists suggest that serotonin can be involved in reality distortion. There is also evidence from studies of animals that serotonin can modulate the effects of dopamine on levels of motor activity. For example, the serotonin 5- $\mathrm{HT}_{3}$ agonist, 2-methyl-5-HT, enhances locomotor activity induced by amphetamine, while the $5-\mathrm{HT}_{3}$ antagonist, ondansetron, can inhibit hyperactivity induced by dopamine infusion in the nucleus accumbens in rats, but does not inhibit normal locomotor

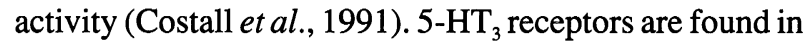
limbic areas, leading Costall et al. to propose that $5-\mathrm{HT}_{3}$ receptors influence mesolimbic dopaminergic function without affecting nigrostriatal dopaminergic activity.

Stein and Wise (1971) proposed that underactivity of the cortical noradrenergic reward system might account for deficits of goal-directed behaviour in schizophrenia. The evidence regarding noradrenergic activity in schizophrenia is inconsistent, possibly because noradrenergic activity varies depending on the state of the illness. There is substantial evidence that noradrenergic activity is low in the stable phase of the illness and high during relapse of florid symptoms (Van Kammen, 1991). Van Kammen proposes that noradrenaline modulates dopaminergic function in schizophrenia. Furthermore, in animals, nor- 
adrenergic activity can modulate dopaminergic function in a region-specific manner. Herve et al. (1982) found that des truction of noradrenergic fibres in the ventral tegmental area in rats reduced dopamine utilization in prefrontal cortex but did not in the nucleus accumbens.

Overall, the evidence indicates that dopamine plays a central role in the modulation of the supervisory mental functions, but dopaminergic activity is itself modulated not only by cortico-subcortical glutaminergic projections, but also by the other monoaminergic neurotransmitters, serotonin and noradrenaline.

\section{PSYCHOSOCIAL FACTORS AND PSYCHOMOTOR DISORDERS}

Because the supervisory mental functions are most relevant when there is ambiguity in what activity is required, the degree to which disorders of these processes are manifest depends greatly on circumstances. It is possible that the severity of the disorder itself can be exacerbated or ameliorated by psychosocial factors. In a study of longstay patients in three mental hospitals, Wing and Brown (1970) demonstrated that an impoverished environment with little social or occupational stimulation was associated with greater tendency for the patients to be mute and apathetic. Furthermore, changes in the level of environmental stimulation and opportunity for self-responsibility were followed by reciprocal changes in psychomotor poverty symptoms. However, overstimulation of patients with schizophrenia is likely to promote relapse with florid symptoms of psychomotor disorganization and/or reality distortion (Malla et al., 1990). Studies of animals provide evidence that links psychosocial factors to dopaminergic activity in the frontal cortex. Rats subjected to isolation have decreased frontal dopaminergic activity and heightened sensitivity to stress (Blanc et al., 1980). While dopamine appears to play a cardinal role in the response of the frontal cortex to stress, noradrenaline and serotonin play a role in the response of the hypothalamic-pituitary-adrenal (HPA) axis by promoting release of adrenocorticotrophic hormone, apparently mediated by corticotrophin releasing factor neurons in the hypothalamus (Delbende et al., 1992). The relationship of the HPA axis response to stress and cortical responses requires further exploration.

\section{TREATMENT STRATEGIES}

In principle, the first issue to consider in treatment of psychomotor disorders is treatment of the underlying primary condition. In practice, this is rarely a fruitful approach because in many instances the underlying problem is neuronal dysplasia or degeneration. However, the existence of common clinical and pharmacological features of psychomotor disorders arising from a variety of different primary conditions, some of which are reversible, implies that aspects of the pathophysiological processes that generate the symptoms are common to psychomotor disorders arising from various causes, and these common aspects are potentially reversible.

The issue of treatment is complex because the evidence suggests that both pharmacological and psychosocial strategies that alleviate psychomotor poverty are prone to exacerbate psychomotor disorganization and reality distortion. In general, enhancement of dopaminergic activity and psychosocial stimulation are likely to be effective in alleviating psychomotor poverty. Dopamine blockade and reduction of unnecessary stimulation are likely to be effective in treating disorganization and reality distortion.

In conditions such as the early phase of Parkinson's disease where there is a negligible predisposition to disorganization or reality distortion, symptomatic treatment with dopaminergic agonists is very successful. In the treatment of mania and of acute episodes of schizophrenia, where the need to control the symptoms of disorganization and reality distortion is paramount, treatment with dopamine blocking agents and reduction of external stimulation is effective.

However, in the case of conditions such as Huntington's chorea, and chronic schizophrenia, where there is a predisposition to psychomotor poverty as well as disorganization and reality distortion, a more complex balancing of treatments is required. The evidence that these three syndromes reflect distinct dimensions of psychopathology implies that the problem is not so much a matter of contradictory treatment objectives, as a need to deal simultaneously with several different requirements. The possibility that anatomically distinct dopaminergic neuronal systems might be involved in different aspects of the regulation of brain activity (Creese and Iverson, 1974; Kelly et al., 1975) suggests that one approach is to seek drugs acting differentially on the different dopaminergic systems. Alternatively, the strategy employed by Goldberg et al. (1991) of combining haloperidol with dextroamphetamine offers the possibility of blocking the subcortical D2 receptors implicated in florid schizophrenic symptoms, while producing an indirect agonist effect at the cortical D1 receptors implicated in psychomotor poverty symptoms. Although Goldberg's preliminary results demonstrating modest improvement in affect and in cognitive performance must be treated with caution, they indicate that this strategy should be explored further.

However, as it is likely that neurotransmitters other than dopamine are involved, pharmacological agents that act on several different neurotransmitter systems might provide an alternative approach. This possibility is consistent with the evidence that clozapine, which acts on a wide variety of neurotransmitter receptors including dopamine D1, D2 and D4 receptors, serotonin 5- $\mathrm{HT}_{2}$ receptors and noradrenaline alpha- 2 receptors, is effective in treating the 
entire gamut of schizophrenic symptoms, including psychomotor poverty, disorganization and reality distortion (Meltzer, 1992).

Reports that a low ratio of the dopamine metabolite, homovanillic acid, to the serotonin metabolite, 5-hydroxyindole acetic acid, is predictive of response to clozapine (Pickar et al., 1992) suggest that restoring the balance between dopaminergic activity and serotoninergic activity is a factor in the action of clozapine. The potential importance of the balance between dopamine and serotonin is reinforced by evidence that drugs such as risperidone that simultaneously block $5-\mathrm{HT}_{2}$ serotonin receptors and D2 dopamine receptors are effective in alleviating core negative schizophrenic symptoms (psychomotor poverty) as well as delusions and hallucinations (reality distortion) (Heylen and Gelders, 1990).

However, there is also evidence that the action of clozapine includes influence on the noradrenergic system. Pickar et al. (1992) found that while clozapine resembles fluphenazine (a typical dopamine blocking antipsychotic drug) in its effects on plasma homovanillic acid, it differs from fluphenazine in producing a substantial increase in plasma noradrenaline, indicating an enhancement of noradrenergic activity. Furthermore, Litman et al. (in press) demonstrated that adding idazoxan, an alpha-2 adrenoreceptor blocking agent which would be expected to increase noradrenergic activity by blocking presynaptic alpha-2 receptors, to concurrent treatment with fluphenazine, alleviates negative symptoms in schizophrenia. Since alpha- 2 agents can modulate ventral tegmental area dopaminergic neurons (Grenhoff and Svensson, 1989), and furthermore, noradrenergic activity in the ventral tegmental area promotes mesocortical but not mesolimbic dopaminergic activity (Herve et al., 1982), it is possible that idazoxan alleviates negative symptoms by producing a selective enhancement of frontal dopaminergic activity.

\section{CONCLUSION}

There appear to be several characteristic patterns of disturbance of supervisory mental processes that occur either alone or in combination, in a variety of different diseases. It is probable that the nature of the primary disease determines which of the characteristic patterns are likely to occur, and also the likelihood that symptoms will either persist or remit spontaneously. However, the neuroanatomical sites and neurotransmitter systems implicated in the production of each of the characteristic patterns of symptoms appear to be the same in different diseases. The evidence from brain imaging studies suggests that the three major syndromes, psychomotor poverty, disorganization and reality distortion, are associated with three different patterns of disturbance in function of association cortex and related subcortical nuclei. The monoamine neurotransmitters, especially dopamine, appear to influence the expression of each of these syndromes. Although a particular neurotransmitter, such as dopamine, might have opposing influences on different syndromes, the differential involvement of different anatomic sites offers the possibility of successful treatment even when different syndromes co-exist.

\section{REFERENCES}

Andreasen NC (1979) Thought, language, and communication disorders. II. Diagnostic significance. Archives of General Psychiatry, 36, 1325-1330.

Arndt S, Alliger RJ and Andreasen NC (1991) The distinction of positive and negative symptoms. The failure of a two-dimensional model. British Journal of Psychiatry, 158, 317-322.

Askinazi C, Weintraub RJ and Karamouz N (1986) Elderly depressed females as a possible subgroup of patients responsive to methylphenidate. Journal of Clinical Psychiatry, 47, 467-469.

Banki CN (1977) Correlation between CSF metabolites and psychomotor activity in affective disorders. Journal of Neurochemistry, 28, 255-257.

Baxter LR, Schwartz JM, Phelps ME, Maziotta JC, Guze BH, Selin CE, Gerner MD and Sumida RM (1989) Reduction in prefrontal cortex glucose metabolism common to three types of depression. Archives of General Psychiatry, 46, 243-250.

Bench CJ, Dolan RJ, Friston KJ, Brown RG, Scott LC and Frackowiak RSJ (in press) Regional cerebral blood flow in depression measured by Positron Emission Tomography: the relationship with clinical dimensions. Psychological Medicine.

Berman KF, Doran AR, Pickar D and Weinberger DR (1993) Is the mechanism of prefrontal function hypofunction in depression the same in depression as in schizophrenia? Regional cerebral blood flow during cognitive activation. British Journal of Psychiatry, 162, 183-192.

Bilder RM, Mukherjee S, Rieder RO and Pandurangi AK (1985) Symptomatic and neuropsychological components of defect states. Schizophrenia Bulletin, 11, 409-419.

Blanc G, Herve D, Simon H, Lisoprawski A, Glowinski J and Tassin JP (1980) Response to stress of mesocortico-frontal dopaminergic neurones in rats after long term isolation. Nature (London), 284, 265-267.

Blumer D and Benson DF (1975) Personality changes with frontal lobe lesions. In: Psychiatric Aspects of Neurological Disease (Eds DF Benson and D Blummer), pp. 151-170. Grune \& Stratton, New York.

Caine ED and Shoulson I (1983) Psychiatric syndromes in Huntington's disease. American Journal of Psychiatry, 140, 728-733.

Cesarec Z and Nyman AK (1985) Differential response to amphetamine in schizophrenia. Acta Psychiatrica Scandinavica, 71, 523-538.

Chiarello RJ and Cole JO (1987) The use of psychostimulants in general psychiatry: a reconsideration. Archives of General Psychiatry, 44, 286-295.

Costal B, Domeney AM, Hagan RM, Kelly ME, Naylor RJ, Oakley NR and Tyers MB (1991) Preclinical evidence for the use of ondansetron in schizophrenia and psychoactive substance abuse. In: Biological Psychiatry, Vol. 2 (Eds G Racagni, N Brunello and T Fukuda), pp. 877-880. Elsevier, Amsterdam. 
Creese I and Iverson SD (1974) A role of forebrain dopamine systems in amphetamine-induced stereotyped behaviour in the rat. Psychopharmacologia, 39, 345-357.

Crow TJ (1980) Molecular pathology of schizophrenia: more than one disease process? British Medical Journal, 280, 1-9.

Daniel DG, Weinberger DR, Breslin DW, Jones JE, Kleinman JE, Zigun JR, Coppola R, Bigalow LB, Berman KF and Goldberg TE (1990) The effects of dopamine agonists on CBF ( ${ }^{133} \mathrm{Xe}$ dynamic SPECT) and negative symptoms in schizophrenia. Schizophrenia Research, 3, 28.

De Ajuriaguerra J (1971) Etude psychopathologique des Parkinsoniens. In: Monoamines, Noyaux Gris Centraux et Syndrome de Parkinson (Eds J de Ajuriaguerra and G Gauthier). George, Geneva.

Delbende C, Delarue C, Lefebre H, Tranchand Bunel D, Szafarczyk A, Mocaer E, Kamoun A, Jegou S and Vaudry H (1992) Glucocorticoids, transmitters and stress. British Journal of Psychiatry, 160, 24-34.

Fibiger HC (1991) The dopamine hypothesis of schizophrenia and mood disorders: contradictions and speculations. In: The Mesolimbic Dopamine System: From Mechanism to Action (Eds P Willner and J Scheel-Kruger). Wiley, New York.

Frith CD and Done J (1989) Experiences of alien control in schizophrenia reflect a disorder in the central monitoring of action. Psychological Medicine, 19, 359-363.

Frith CD, Friston KJ, Liddle PF and Frackowiak RSJ (1991) Willed action and the prefrontal cortex in man: a study with PET. Proceedings of the Royal Society B, 244, 241-246.

Frith CD, Friston KJ, Liddle PF and Frackowiak RSJ (1992) PET imaging and cognition in schizophrenia. Journal of the Royal Society of Medicine, 85, 222-224.

Friston KJ, Grasby PM, Bench CJ, Frith CD, Cowen PJ, Liddle PF, Frackowiak RSJ and Dolan RJ (1992) Measuring the neuromodulatory effects of drugs in man with positron emission tomography. Neurosciences Letters, 141, 106-110.

Fuster JM (1980) The Prefrontal Cortex. Raven Press, New York.

Gallhofer B, Trimble MR, Frackowiak R, Gibbs J and Jones T (1985) A study of cerebral blood flow and metabolism in epileptic psychosis using positron emission tomography and oxygen. Journal of Neurology, Neurosurgery and Psychiatry, 48 , 201-206.

Geraud G, Arne-Bes MC, Guell A and Bes A (1987) Reversibility of haemodynamic hypofrontality in schizophrenia. Journal of Cerebral Blood Flow and Metabolism, 7, 9-12.

Goldberg TE, Bigelow LB, Weinberger DR, Daniel DG and Kleinamn JE (1991) Cognitive and behavioural effects of the coadministration of dextroamphetamine and haloperidol in schizophrenia. American Journal of Psychiatry, 148, 78-84.

Goldman-Rakic PS (1988) Topography of cognition: parallel distributed networks in primate association cortex. Annual Review of Neuroscience, 11, 137-156.

Goodwin FK, Brodie HK, Murphy DL and Bunney WE (1970) Administration of a peripheral decarboxylase inhibitor with L-dopa to depressed patients. Lancet, i, 908.

Grenhoff J and Svensson TH (1989) Clonidine modulates dopamine cell firing in the rat ventral tegmental area. European Journal of Pharmacology, 165, 11-18.

Harlow JM (1848) Passage of an iron rod through the head. Boston Medical and Surgical Journal, 39, 389-393.

Hecker E (1871) Die Hebephrenia. Virchows Archiv fur Pathologie und Anatomie, 52, 394-429.

Herve D, Blanc G, Glowinski J and Tassin JP (1982) Reduction of dopamine utilization in the prefrontal cortex but not in the nucleus accumbens after selective destruction of noradrenergic fibres innervating the vental tegmental area in the rat. Brain Research, 237, 510-516.

Heylen SLE and Gelders YG (1990) Combined serotonin 5-HT and dopamine D2 receptor antagonism in the treatment of schizophrenia. Schizophrenia Research, 3, 46-47.

Huber SJ and Paulson GW (1985) The concept of sub-cortical dementia. American Journal of Psychiatry, 142, 1312-1317.

Janowsky DS and Davis JM (1976) Methyl phenidate, dextroamphetamine, and levanfetamine. Archives of General Psychiatry, 33, 304-308.

Kaczmarek BLJ (1984) Neurolinguistic analysis of verbal utterances in patients with focal lesions of frontal lobes. Brain and Language, 21, 52-58.

Kahlbaum KL (1874) Catatonia (Transl. Y Levij and T Pridan, 1973). Johns Hopkins University Press, Baltimore.

Kelly PH, Seviour P and Iverson SD (1975) Amphetamine and apomorphine responses in the rat following 6-OHDA lesions of the nucleus accumbens septi and corpus striatum. Brain Research, 94, 507-522.

Kleist K (1934) Gehirnpathologie. Barth, Leipzig.

Kolb B and Wishaw IQ (1980) Fundamentals of Human Neuropsychology. Freeman, San Francisco.

Kraepelin E (1919) Dementia Praecox and Paraphrenia (Transl. RM Barclay, facsimile edn published 1971). Kreiger, New York.

Kraepelin E (1920) Die Erscheinungsformen des Irresciens. Transl. H Marshall, in: Themes and Variations in European Psychiatry (Eds SR Hirsch and M Shepherd), 1974. John Wright, Bristol.

Liddle PF (1984) Chronic schizophrenic symptoms, cognitive function and neurological impairment. Membership examination thesis, Royal College of Psychiatrists, London.

Liddle PF (1987a) The symptoms of chronic schizophrenia: a re-examination of the positive-negative dichotomy. British Journal of Psychiatry, 151, 145-151.

Liddle PF (1987b) Schizophrenic syndromes, cognitive performance and neurological dysfunction. Psychological Medicine, 17, 49-57.

Liddle PF and Morris D (1991) Schizophrenic syndromes and frontal lobe performance. British Journal of Psychiatry, 158 , 340-345.

Liddle PF, Friston KJ, Frith CD, Jones T, Hirsch SR and Frackowiak RSJ (1992a) Patterns of cerebral blood flow in schizophrenia. British Journal of Psychiatry, 160, 179-186.

Liddle PF, Friston KJ, Frith CD and Frackowiak RSJ (1992b) Cerebral blood flow and mental processes in schizophrenia. Journal of the Royal Society of Medicine, 85, 224-227.

Lindstrom LH (1985) Low HVA and normal 5-HIAA CSF levels in drug-free schizophrenic patients compared to healthy volunteers: correlations to symptomatology and heredity. Schizophrenia Research, 14, 265-274.

Litman RE, Hong WW, Weissman MD, Su T, Potter WZ and Pickar D (In press) Idazoxan, an alpha2 antagonist, augments fluphenazine in schizophrenic patients: a pilot study. Journal of Clinical Psychopharmacology.

Luria A (1966) Higher Cortical Functions in Man. Basic Books, New York.

Malla A, Cortese L and Shaw T (1990) Life events and relapse in schizophrenia: a prospective one year follow-up study. Social Psychiatry and Psychiatric Epidemiology, 25, 221-224.

Matussek N, Benkert O, Schneider K, Otten H and Pohlmeir H (1970) L-dopa plus decarboxylase inhibitor in depression. Lancet, ii, 660 . 
Meltzer HY (1992) Dimensions of outcome with clozapine. British Journal of Psychiatry, 160 (Suppl. 17), 46-53.

Morgenson GJ and Yim CY (1981) Electrophysiological and neuropharmacological behavioural studies of the nucleus accumbens and implications for its role as a limbic-motor interface. In: The Neurobiology of the Nucleus Accumbens (Eds RB Chronister and RF DeFrance), pp. 220-229. Haer Institute, Brunswick.

Morice RD and Ingram JCL (1982) Language analysis in schizophrenia: diagnostic implications. Australian and New Zealand Journal of Psychiatry, 16, 11-21.

Neary D, Snowden JS, Northen B and Goulding P (1988) Dementia of frontal lobe type. Journal of Neurology, Neurosurgery and Psychiatry, 51, 353-361.

Norman DA and Shallice T (1980) Attention to action: willed and automatic control of behaviour. Centre for Human Information Processing (Technical Report, No. 99).

Pardo JV, Pardo PJ, Janer KW and Raichle ME (1990) The anterior cingulate mediates processing selection in the Stroop attentional conflict paradigm. Proceedings of the National Academy of Sciences, 87, 256-259.

Peralta V, de Leon J and Cuesta MJ (1992) Are there more than two syndromes in schizophrenia? A critique of the positivenegative dichotomy. British Journal of Psychiatry, 161, 335-343.

Pickar D, Owen RR, Litman RE, Konica E, Gatierrez R and Rappaport MH (1992) Clinical and biological response to clozapine in patients with schizophrenia. Archives of General Psychiatry, 49, 345-353.

Playford D, Jenkins HI, Passingham R, Nutt J, Frackowiak RSJ and Brooks DJ (1992) Impaired mesial frontal and putamen activation in Parkinson's disease: a PET study. Annals of Neurology, 32, 151-161.

Pycock CJ, Kerwin RW and Carter CJ (1980). Effects of lesion of cortical dopamine terminals on sub-cortical dopamine receptors in rats. Nature (London), 286, 74-77.

Reibaud M, Blanc G, Studler J, Glowinski J and Tassin J (1984) Non-DA prefronto-cortical efferents modulate $D$, receptors in the nucleus accumbens. Brain Research, 305, 43-50.
Robbins TW and Sahakian BJ (1983) Behavioural effects of psychomotor stimulant drugs: clinical and neuropsychological implications. In: Stimulants: Neurochemical, Behavioural and Clinical Perspectives (Ed. I Creese). Raven Press, New York.

Sawaguchi T and Goldman-Rakic PS (1991) D1 dopamine receptors in prefrontal cortex: involvement in working memory. Science, $251,947-951$.

Shallice T (1989) From Neuropsychology to Mental Structure. Cambridge University Press, Cambridge.

Stein L and Wise CD (1971) Possible etiology of schizophrenia: progressive damage to the noradrenergic reward system by 6-hydroxy dopamine. Science, 171, 1032-1036.

Trimble M (1992) Neurological models of schizophreniaregional implications. Clinical Neuropharmacology, 15 (Suppl. 1A), 395-396.

Van Kammen DP (1991) The biochemical basis of relapse and drug response in schizophrenia: review and hypothesis. Psychological Medicine, 21, 881-895.

Van Praag HM, Korf J, Lakke JPWF and Schut T (1975) Dopamine metabolism in depression, psychoses, and Parkinson's Disease: the problem of the specificity in biological variables in behaviour disorders. Psychological Medicine, 5, 138.

Weinberger DR, Berman KF and Illowsky BP (1988) Physiological dysfunction of the dorsolateral prefrontal cortex in schizophrenia III. A new cohort and evidence for a monoaminergic mechanism. Archives of General Psychiatry, 45, 609-615.

Wing JK and Brown GW (1970) Institutionalization and Schizophrenia. Cambridge University Press, Cambridge.

Wolfe N, Katz DL and Albert ML (1990) Neuropsychological profile linked to low dopamine in Alzheimer's disease, major depression and Parkinson's disease. Journal of Neurology, Neurosurgery and Psychiatry, 53, 915-917.

(Received 10 January 1993; accepted 15 February 1993) 


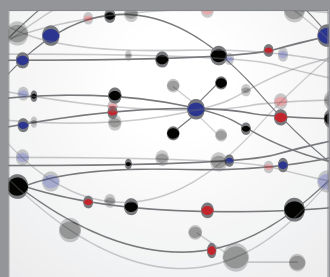

The Scientific World Journal
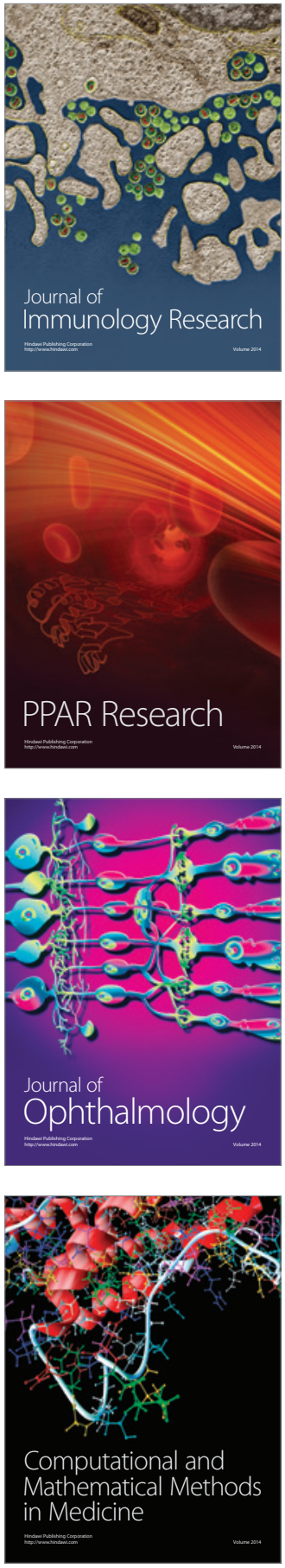

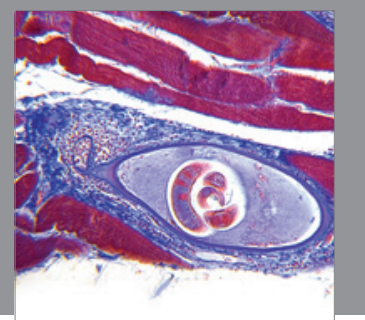

Gastroenterology

Research and Practice
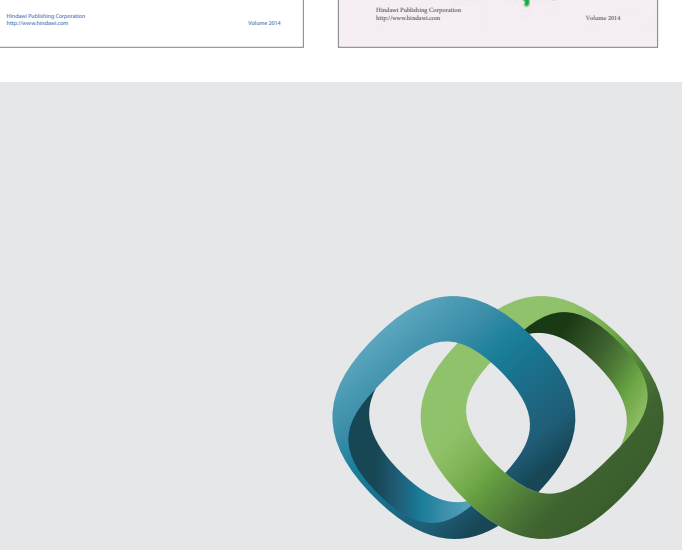

\section{Hindawi}

Submit your manuscripts at

http://www.hindawi.com
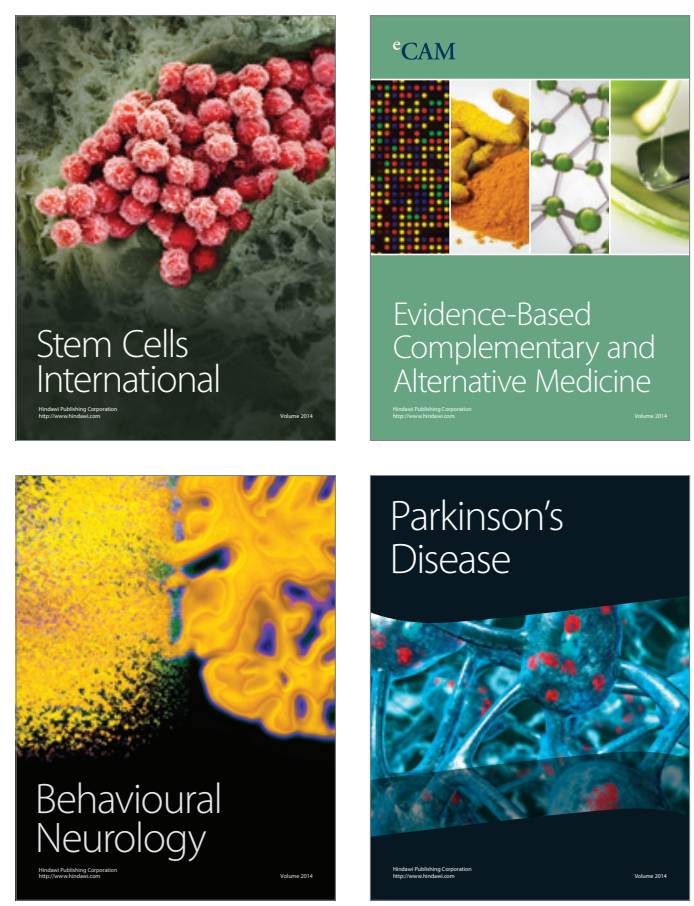

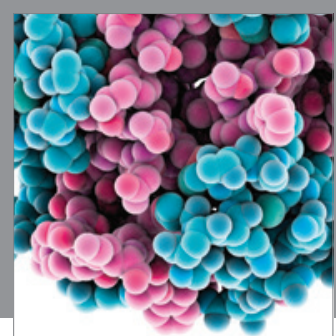

Journal of
Diabetes Research

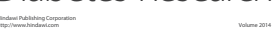

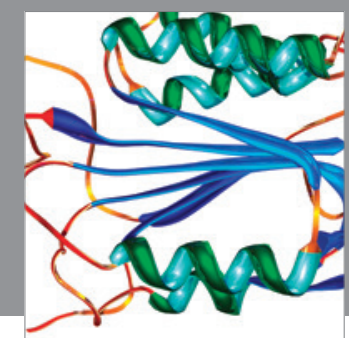

Disease Markers
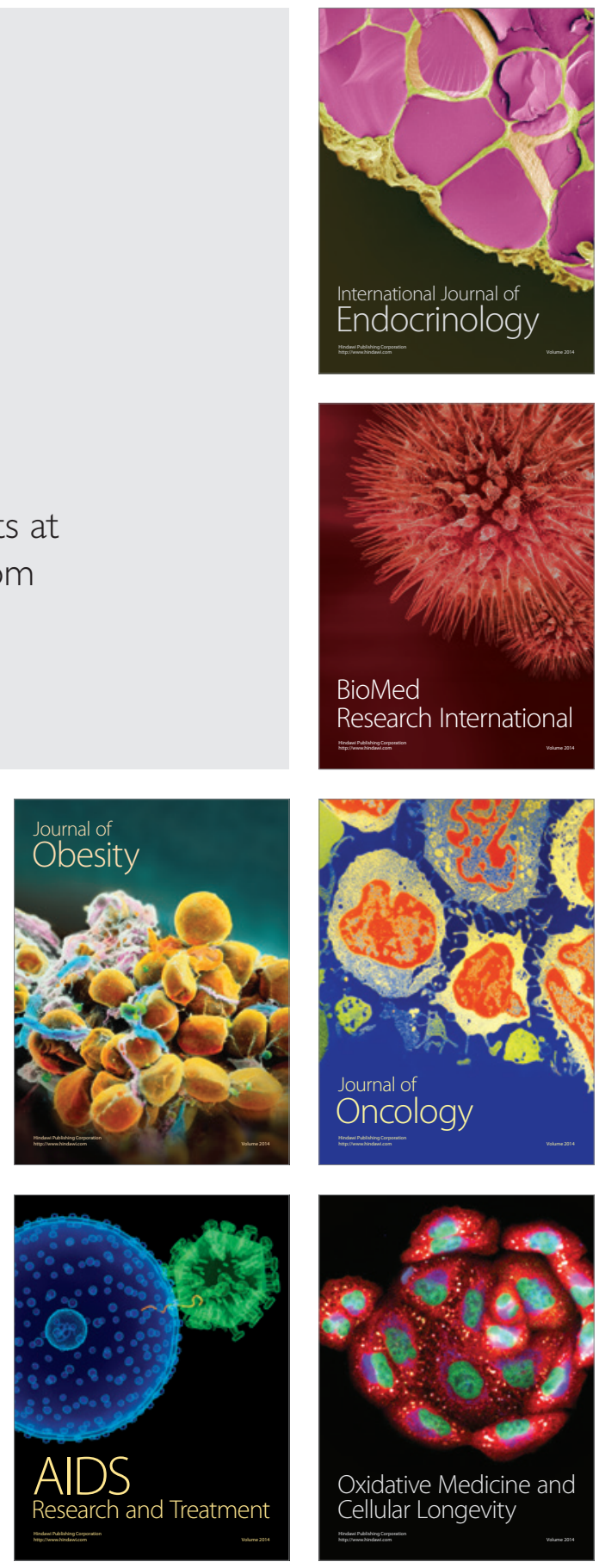